\title{
South African universities, research and positive psychology
}

\author{
A. M. Viviers \\ Department of Industrial and Organisational Psychology \\ University of South Africa \\ Pretoria, South Africa \\ e-mail:vivieam@unisa.ac.za \\ S. Coetzee \\ Department of Industrial and Organisational Psychology \\ University of South Africa \\ Pretoria, South Africa
}

\begin{abstract}
A decline in institutional research activity, like that attributed to most South African universities, is alarming because it jeopardises a country's ability to take advantage of world-wide advances in science and technology as well as its capacity to absorb and use new knowledge. However, criticism like this might not be applicable to all areas of research at higher education institutions. The purpose of this article is to highlight pioneering and fundamental contributions by South African researchers to establishing a new paradigm in psychology, namely positive psychology. The article provides an overview of the national and international historic development of this field. Current and completed South African research within this field was analysed, and results reflect the type of research as well as contributing institutions from higher education.
\end{abstract}

\section{INTRODUCTION}

Linley, Joseph, Harrington and Wood (2006) define positive psychology as the scientific study of optimal human functioning. 'At the meta-psychological level, it aims to redress the imbalance in psychological research and practice by calling attention to the positive aspects of human functioning and experience. At the pragmatic level, it is about understanding the wellsprings, processes and mechanisms that lead to desirable outcomes' (Linley, Joseph, Harrington and Wood 2006, 5).

Positive psychology, applied to the domain of organisational psychology, provides an expanded view of how organisations can create a sustained competitive advantage. This application recently became known as Positive Organisational Scholarship (POS). It offers fresh attention to enablers (like processes, capabilities, structures and methods), motivations (like unselfishness and altruism), and outcomes or effects (like meaningfulness, vitality and high-quality relationships) that can help organisations thrive (Cameron, Dutton and Quinn 2003). 
South African organisations are faced with enormous challenges regarding employee wellness. Research in the field of positive psychology ${ }^{1}$ by South African researchers indicates significant contributions that create an expert knowledge base regarding aspects related to employee wellness. The purpose of this article is to point out the pioneering and fundamental contribution of South African research within this specific domain that aids in building this new and internationally developing science.

Most of the research reported on in this article was done at higher education institutions in South Africa. Higher education plays a fundamental role in the economic, social, cultural and educational development of an economic society, in particular in a developing country like South Africa. Our country is redressing the challenge of past inequalities and engaged in transforming the higher education system to serve a new social order, to meet pressing national needs and to respond to new realities and opportunities. This initiative leads to laying down foundations for the development of a learning society which can stimulate, direct and mobilise the creative and intellectual energies of all the people towards meeting the challenge of reconstruction and development (Education White Paper 1997).

The Education White Paper (1997) recognises that research, a core function of higher education, plays a central role in the production, advancement and dissemination of new knowledge and the development of high-level human resources for the facilitation of economic growth. The Draft National Plan for Higher Education (Ministry of Education $2001 \mathrm{sec}$. 5) therefore sets out 'to sustain current research strengths and to promote the kinds of research and other knowledge outputs required to meet national development needs, which will enable the country to become competitive in a new global context', as its strategic objective.

In 2001 the Ministry of Education (in the Draft National Plan for Higher Education in South Africa 2001) commented that, despite the strong emphasis in the White Paper on the need to develop research capacity and output, the capacity, distribution and outcomes of the higher education research system remain a cause for concern. In this regard, it has previously been mentioned that a lack of research is one of the major shortcomings of many, if not most, South African universities (Malan 1998). Despite these criticisms, some higher education institutions have developed internationally competitive research and teaching capacities and their academic expertise can be seen as national assets (Strydom and Fourie 1999).

South African universities are currently involved in research that forms part of a world-wide initiative to formalise the field of positive psychology, a new emerging paradigm in psychology research and application. This article will focus on the progress of research in the field of positive psychology in South Africa over the last 36 years, indicating the expertise knowledge-base that was built up in this process.

In the opening article of the recently launched Journal of Positive Psychology, Linley, Joseph, Harrington and Wood (2006) ask questions like 'What is positive psychology? Where has it come from? Where is it now? Where is it going?' in an attempt to review 


\section{A. M. Viviers and S. Coetzee}

the progress and possible future direction of the field of positive psychology. The latter two questions can be echoed from a specifically South African perspective. Research done in the field of positive psychology in South Africa and the contributions of various universities are reviewed. An attempt is made to point to possible future directions for research in this field and possible joint ventures between researchers and institutions.

\section{HISTORICAL BACKGROUND}

Even though the paradigm of positive psychology was publicly launched in 1998 by Martin EP Seligman (1999) in his Presidential Address to the American Psychological Association, it has a research tradition that goes back decades (Linley and Joseph 2004). The Greek philosopher Aristotle's treatises on eudaimonia already reflect interest in what is good about humans and their lives and in optimal human functioning (Linley and Joseph 2004). Furthermore, within the very origins of modern psychology, James (in his writings on 'healthy mindedness' of 1902, 1987) was interested in optimal human functioning and the role that transcendent experiences may play in stimulating this. Since then, Jung (1933) investigated how people can become all that they can be through individuation, Jahoda (1958) asked questions about what might constitute mental health, and Allport (1961) echoed the theme of Jung within his work on the mature individual. Some of the other forerunners of positive psychology are from the paradigm of humanistic psychology which studied the fully functioning person (Rogers 1961), self-actualisation and healthy individuals (Maslow 1968) (cf. Linley and Joseph 2004; Linley, Joseph, Harrington and Wood 2006). An article by Strümpfer (2005) titled Standing on the shoulders of giants: notes on early positive psychology (psychofortology) provides a comprehensive overview of the contribution of these authors, and other diverse contributions by predecessors and well-known authors to the paradigm of positive psychology. However, these contributions have remained isolated from each other and lacked any shared language or common identity (Linley and Joseph 2004). Seligman (in Linley, Joseph, Harrington and Wood 2006) also realised that psychology had largely neglected some of its pre-World War II missions to cure mental illness, help people to lead more productive and fulfilling lives and identify and nurture high talent. Instead, psychology has been largely dominated by a pathogenic paradigm, and as stated by Strümpfer (2005), psychologists' main activities centred on the assessment and treatment of pathos (suffering). Based on this, Seligman decided to use his APA presidency to initiate a shift in psychology's focus towards a more positive psychology (Seligman 1999).

\section{POSITIVE PSYCHOLOGY ACTIVITIES INTERNATIONALLY}

After the public launch of the new field of positive psychology, the field flourished and the works of researchers like Csikszentmihalyi, Diener, Jamieson, Peterson and Valiant, who also form the Positive Psychology Steering Committee, were united. The work of these and other researchers culminated in the publication of numerous positive 
psychology books, 16 special journal issues since 2000, and the establishment of positive psychology networks that span the globe. The Journal of Positive Psychology was launched in 2006. Other accomplishments that mark the extremely rapid progress of the field are undergraduate, postgraduate and even high school courses on positive psychology taught the world over, Positive Psychology Centres at several major universities, and active websites and list servers (see Seligman 2004 and Seligman, Steen, Park and Peterson 2005 for a full review of these and other accomplishments).

Parallel to this new movement in psychology, Positive Organisational Scholarship (POS) is developing as an exciting new movement in organisational studies. It focuses on the dynamics that lead to developing human strength, producing resilience and restoration, fostering vitality, and cultivating extraordinary individuals, units and organisations. Positive Organisational Scholarship is based on the premise that understanding how to enable human excellence in organisations will unlock potential, reveal possibilities, and facilitate a more positive course of human and organisational welfare (Cameron, Dutton and Quinn 2003).

At the recently held 3rd European Conference on Positive Psychology during July 2006 in Portugal, attending members were challenged to contemplate, in the next two years, the current place of positive psychology - whether it should grow into a science on its own or if it should be included in the broader field of psychology. This also reflects the views expressed by Linley et al. (2006) in their review of positive psychology.

\section{POSITIVE PSYCHOLOGY ACTIVITIES IN SOUTH AFRICA}

Similar to the strands of positive psychology mentioned above in the historical background, researchers in South Africa focused on self-actualisation in the late 1970s and 80s (cf. Van Zyl 1979; Harmse 1980). The first prominent acknowledgement of a new field of study in South Africa was done by Strümpfer in 1990 in his article Salutogenesis: a new paradigm, based on the work of Antonovsky (1987) regarding the core construct of salutogenesis, namely, a sense of coherence. In this article, Strümpfer (1990) already noticed and commented on the significant impact that a construct such as sense of coherence might have on how work is approached and performed. In 1995 Strümpfer proposed that the construct of salutogenesis (meaning the origin of health) should be broadened from an emphasis on health only to also include strengths, and subsequently coined the term fortology (meaning the origin of strengths) (Strümpfer 1995). Wissing and Van Eeden $(1997,5)$ went a step further and contended 'that in this domain, not only the origins of psychological well-being should be studied, but also the nature, manifestations and consequently ways to enhance psychological well-being and develop human capacities'. They therefore suggested the emergence of a new subdiscipline which they called psychofortology (Wissing and Van Eeden 1997).

Other activities that mark the progress in the field of positive psychology in South Africa include the First South African National Wellness Conference held in Port Elizabeth in 2000 and the 1st and 2nd South African Work Wellness Conferences held in Potchefstroom in 2002 and 2004 respectively, culminating in the South African 


\section{A. M. Viviers and S. Coetzee}

Conference on Positive Psychology: Individual, Social and Work Wellness, held in Potchefstroom in 2006. The directed research programmes and units of Psychofortology and Work Wellness were also initiated at the North-West University and are currently involved in international and trans-university research projects, funded by the National Research Foundation (NRF) of South Africa.

It is evident that positive psychology is a field growing rapidly. One can therefore ask where the field has come from, where is it now and where is it going?

\section{AIMS}

The aims of this article are to:

- report on the progress of research in the field of positive psychology in the South African context

- reflect on the contributions of various universities

- recommend possible directions for future South African research and joint ventures.

\section{METHODOLOGY}

\section{Data collection}

A search has been done by means of the South African Bibliographic Information Network (SABINET), an online information technology service.

Databases searched were current and completed research projects in South Africa, articles from South African journals, online full-text articles from South African journals, publications, and theses and dissertations at South African universities. Since all these databases only reflect South African publications, international publications by South African authors are not reflected in the results of this article. The data included studies from 1979 to December of 2005.

Keywords for the search were positive psychology, salutogenesis, fortigenesis, psychofortology, positive mental health, subjective well-being, employee wellness or well-being, emotional wellness or well-being, social wellness or well-being, sense of coherence, locus of control, self-efficacy, hardiness, learned resourcefulness, resilience, potency, character strengths, signature strengths, emotional intelligence, hope, optimism, mindfulness, self-regulation, gratitude, toughness, wisdom, spirituality, flow, happiness, positive emotions or emotionality, self-actualisation, self-determination, engagement, appreciative enquiry, eustress, coping, mastery, fully functioning personality, agency, stren, ego-resiliency.

\section{Data analysis and interpretation}

One of the aims of this article is to provide a review of research being done in South Africa in the field of positive psychology. In order to do this, the field needs to be 
explored and its taxonomy established. Since Strümpfer (2005) pointed out that positive psychology in fact stands on the shoulders of giants, as discussed above, the scope of this investigation was broadened to include constructs also related to aspects of human optimal functioning. A clear and appropriate framework is needed to categorise the many divergent constructs in comprehensive and logical clusters.

International research provided some possible classification systems but these could not fulfil the requirements of such a comprehensive framework as was required for this research. South African literature was reviewed and additional classifications were utilised to add to the international classification systems.

\section{International classification systems of positive psychology constructs}

The new paradigm of positive psychology stands at a crossroads (Linley et al. 2006) and offers a grand integrative vision that could change the face of psychology. This is reflected in a variety of perspectives on how the field can be defined and the uncertainty about classification systems. Linley et al. (2006) clearly point out that positive psychology does not have a taxonomic influence and that the challenge is now to expand a classification context in order to synthesise the diverse states, traits and outcomes in relation to each other. These domains of psychological strengths should be clearly understood in proportion to, relation with and interaction with each other.

In terms of formalising the new field of positive psychology, different views from a few forerunners of the field represent efforts to define its taxonomy and scope since its inception in 2000 (cf. Seligman and Csikszentmihalyi 2000; Linley et al. 2006; Strümpfer 2005; Wissing 2000).

Seligman and Csikszentmihalyi $(2000,5)$ initially defined the field of positive psychology at the subjective level as comprising

- valued subjective experiences:

- past: well-being, contentment, satisfaction

- present: flow, happiness

- future: hope, optimism

- individual and group levels:

- individual (positive individual traits): capacity for love and vocation, courage, interpersonal skill, aesthetic sensibility, perseverance, forgiveness, originality, future mindedness, spirituality, high talent, wisdom

- group (civic virtues and the institutions that move individuals toward better citizenship): responsibility, nurturance, altruism, civility, moderation, tolerance, work ethic

However, the challenge remained to find an appropriate categorisation framework to effectively group the numerous aspects and concepts that fall under the broad terms of 


\section{A. M. Viviers and S. Coetzee}

the three major (currently related, but distinct) families of health-oriented alternatives, namely primary prevention, wellness-enhancement and most recently positive psychology (Cowen and Kilmer 2002). Peterson and Seligman (2004), however, are of the opinion that positive psychology should be distinguished from the humanistic psychology of the 1960s and 1970s and from the positive thinking movement in its reliance on empirical research to understand people and the lives they lead. They cite numerous good examples of ongoing psychological research that fit under the positive psychology umbrella, but admit that the new field lacks a common vocabulary that agrees on the positive traits and allows psychologists to move among instances of them. This need for a common classification system and vocabulary led to the development of a handbook that classifies character strengths and virtues namely Character strengths and virtues: a handbook and classification (Peterson and Seligman 2004).

The publication of the January 2000 edition of the American Psychologist on positive psychology elicited both praise and critique. A need explicitly expressed by Cowen and Kilmer (2002), is for the development of a comprehensive, overall guiding theory of positive psychology and the outcomes that are central to such a theory. They therefore criticised the lack of a cohesive foundational theoretical framework and listed the 60+ (presumably central) positive psychology outcomes addressed in only 16 articles in the American Psychologist of January 2000. These positive psychology target outcome variables were not grouped or clustered in any particular manner, and the need for a proper classification system is therefore emphasised. They are of the opinion that relevant dependant variables should be clearly defined and interrelationships and co-occurrences among them established. In doing so, the $60+$ different variables will be condensed to a finite number of clearly defined factors whose relationships and relevance to positive outcomes are self-evident. This, they claim, could help to promote desired outcomes pragmatically, parsimoniously and functionally.

\section{South African classification systems of positive psychology constructs}

Strümpfer (1990) linked the five constructs of sense of coherence, hardiness, potency, stamina and learned resourcefulness to the salutogenic paradigm and so provided a useful frame of reference and guidelines for future research in South Africa. In similar fashion Strümpfer (1995) elaborated on his previous classification and, based on the views of Antonovsky (1991), included self-efficacy and locus of control in the salutogenic constructs. After the term fortigenesis (Strümpfer 1995) was introduced in South Africa, he focused on related constructs (Strümpfer 2003) and listed engagement, meaningfulness, subjective well-being, positive emotions and proactive coping as fortigenic constructs (under the general heading of resilience). He also refers to restorative places, flow activities, interpersonal flourishing and balint groups.

Wissing (2000) is of the opinion that there are many gaps in our knowledge of wellness (the broad term also used for the field of health-oriented alternatives) and expressed a need for the development of a sound scientific foundation for the discipline of positive 
psychology. One of these gaps is the identification of categories of constructs to use for clustering purposes related to the field of positive psychology. These observations are echoed by Cowen and Kilmer (2002) and Linley et al. (2006).

Wissing (2000), in her overview on the construct clarification of wellness and her proposed framework for future research and practice, explained that wellness promotion refers, on a practical and empirical level, to the enhancement of strengths on individual, group and community levels in various contexts. She mentioned broad overarching constructs related to the hypothesised main components of wellness (physical, emotional, cognitive, spiritual, social, behavioural, occupational and ecological) and positive traits (sense of coherence, positive self-esteem, humour, flow, resilience, wisdom and optimistic expectations) as well as positive personality traits (dispositional optimism, self-organisation, self-directedness, adaptiveness, wisdom and exceptional performance). This overview by Wissing (2000) is in line with the basic views of Seligman and Csikszentmihalyi (2000).

Strümpfer (2000) commented on the January 2000 American Psychologist and referred to the range of constructs, ways of thinking and practical applications in the fields of fortology and positive psychology. He made an observation about the diversity of the field of psychofortology and related disciplines represented by the published articles. Strümpfer (2000) was of the opinion that the paradigm of positive psychology, as well as the newly named subdiscipline of psychofortology, is evolving rapidly. Similar views are again expressed by Linley et al. (2006).

\section{The categorisation framework used in this article}

Literature on positive psychology points to a variety of broad theories, models and fields that indicate a trend to optimise human strengths. The science of strengths and optimisation can include references to optimal human functioning, holistic and/or subjective well-being, salutogenesis, fortigenesis, psychofortology, (more generally referred to as fortology), primary prevention (coping), wellness enhancement and positive psychology. This science of strengths investigates states, traits, outcomes, psychological strengths, constructs, positive qualities, virtues, variables and concepts in individuals, groups and institutions. For categorisation purposes it was necessary to combine existing theoretical frameworks and classification systems (as discussed above) into a more comprehensive compilation for categorisation purposes. In conceptualising a workable categorisation framework, the three fields of positive psychology (Seligman and Csikszentmihalyi 2000; Seligman 2002) formed the basis for the categorisation framework in this article. The proposed categorisation framework is shown in Figure 1. The authors decided to categorise the studies (research data), first of all, related to individuals, groups and institutions. Secondly, on the individual level, valued subjective experiences and emotions (in the past, present and future) were differentiated from positive individual traits, states, skills, characteristics, virtues, strengths and constructs. These were subsequently categorised into early positive psychological constructs (constructs 
A. M. Viviers and S. Coetzee

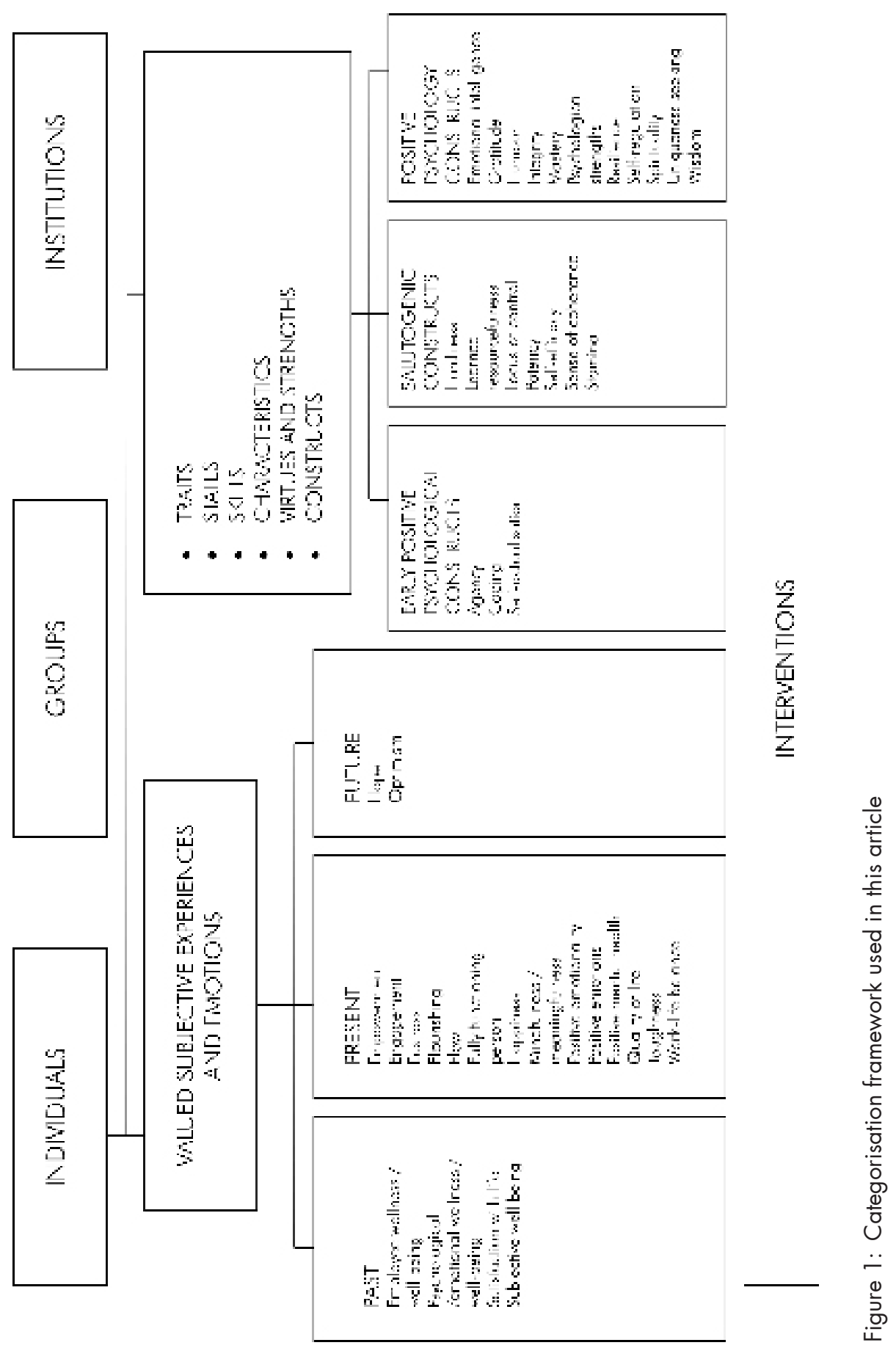

